\title{
Un vaccin homéopathique contre la grippe?!
}

swissmedic

Correspondance:

Swissmedic

Marktkontrolle Arzneimittel

Dr Stefan Borner

Hallerstrasse 7

CH-3000 Berne 9

stefan.borner@swissmedic.ch

\section{Introduction}

La question sur la vaccination contre la grippe dite «porcin» a animé les débats pendant les deux dernières périodes grippales en raison des risques qu'elle peut engendrer. Les craintes exprimées au sujet des adjuvants contenus dans ces vaccins ont également incité de nombreuses personnes à rechercher des alternatives.

Certains spécialistes et membres du corps médical ont alors proposé à leurs patients un «vaccin homéopathique contre la grippe». Il faut savoir que les recommandations de ce type sont trompeuses et mettent fortement en danger la vie des patients. Les patients à risque, auxquels l'OFSP recommande vivement de se faire vacciner au moyen du vaccin antigrippal disponible, pourraient à tort croire qu'ils sont protégés en utilisant ces préparations homéopathiques. Le présent article vise à expliquer les possibilités et les limites de ces préparations.

\section{Terminologie déroutante}

Swissmedic estime que l'utilisation du terme «vaccin homéopathique contre la grippe» induit en erreur. Les préparations homéopathiques qui sont employées pour traiter certains symptômes grippaux n'ont aucun point commun avec les vaccins au sens courant du terme. Selon les principes classiques de l'homéopathie, les médicaments homéopathiques n'ont en règle générale pas d'effet préventif. Par conséquent,

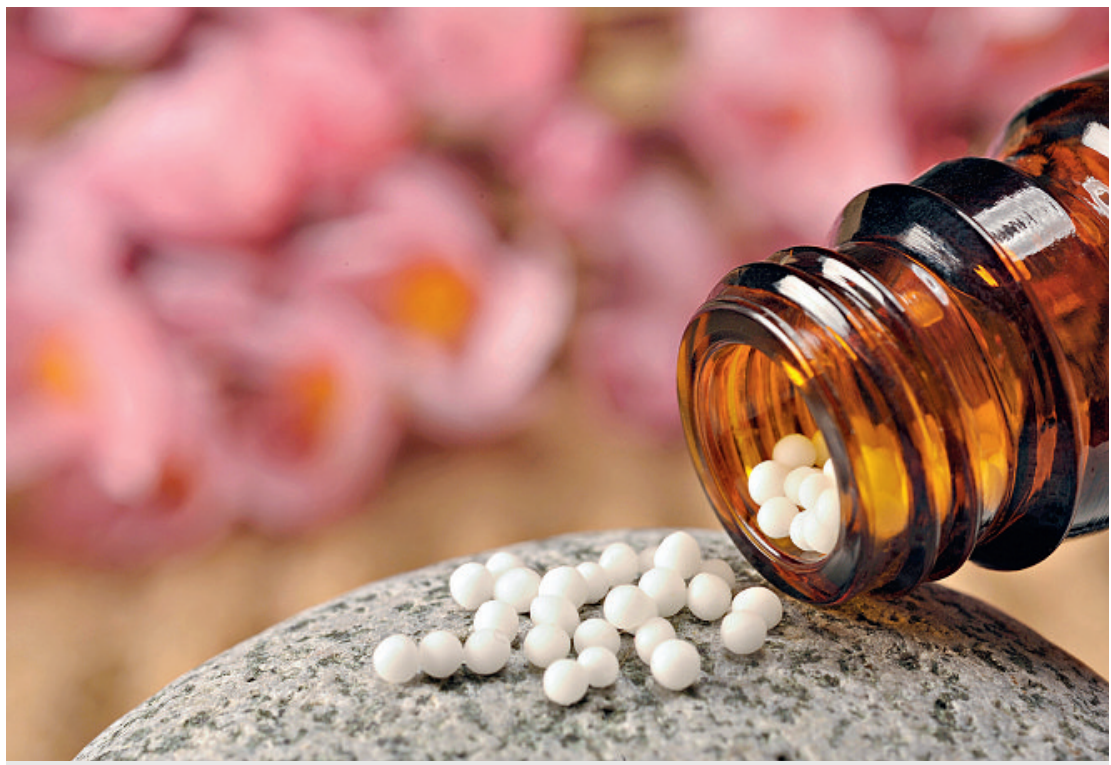

La promotion auprès du public et la vente de préparations homéopathiques en tant que «vaccin homéopathique contre la grippe» sont illicites. ils ne devraient en théorie être utilisés qu'après l'apparition de symptômes pathologiques précis (un spécialiste ou un membre du corps médical disposant de l'autorisation requise sélectionne le remède en appliquant le principe de similitude et en s'appuyant sur le profil de ce dernier).

Vous trouverez ci-dessous quelques informations plus détaillées sur les deux principaux remèdes homéopathiques que certains spécialistes et professionnels de la santé vendent à tort comme des «vaccins homéopathiques contre la grippe» dans le commerce de détail.

\section{Influenzinum}

Influenzinum (ou Influenzinum Nosode) est une préparation homéopathique qui est fabriquée en général à partir d'un vaccin antigrippal transformé et dilué par étapes selon les principes de l'homéopathie. Toutes les préparations homéopathiques Influenzinum qui sont commercialisées avec un numéro d'autorisation Swissmedic ont été approuvées conformément à l'ordonnance sur les médicaments complémentaires et les phytomédicaments (OAMédcophy; RS 812.212.24) en vue d'être vendues sans indication (article 17, alinéa 1 et article 19ss OAMédcophy). Par conséquent, il est interdit de faire leur promotion en précisant l'indication ou le dosage. Les supports publicitaires (encarts dans la presse, dépliants, notices d'emballage, présentoirs, présentoirs de comptoir et autocollants) sur lesquels figureraient des données de ce type sont illégaux. Il en va de même pour les préparations Influenzinum qui sont encore commercialisées à l'heure actuelle en application des dispositions transitoires prévues à l'article 33 de l'OAMédcophy.

Les préparations homéopathiques qui ont été autorisées sans indication peuvent être uniquement recommandées ou remises dans le cadre de traitements individuels. Des spécialistes ou des professionnels de la santé habilités à prescrire ces traitements tiendront compte du profil du médicament le plus approprié à leur patient.

La mention de certaines vertus thérapeutiques, la promotion auprès du public et la vente d'Influenzinum en tant que «vaccin homéopathique contre la grippe» sont donc illicites.

\section{Oscillococcinum}

Cette préparation est fabriquée à partir de foie et de cœur de canard qui sont transformés puis dilués par étapes selon les principes de l'homéopathie (anas barbariae hepatis et cordis extractum 200K). Selon l'infor- 
mation destinée aux patients sur ce médicament, cette préparation est autorisée pour les usages suivants: «Selon la conception homéopathique, Oscillococcinum peut être utilisé en cas de traitement préventif de la grippe, d'état grippal à son début et d'état grippal déclaré».

Ni le distributeur de ce remède ni les détaillants n'ont donc l'autorisation de vendre Oscillococcinum comme un «vaccin homéopathique contre la grippe», puisque cette description ne correspond pas aux données qui ont été approuvées par Swissmedic. Le fait de parler de «vaccin homéopathique contre la grippe» sous-entend en effet que cette préparation a le même effet qu'un vaccin conventionnel contre la grippe. Or un véritable vaccin contre la grippe renferme différents virus grippaux inactivés sélectionnés chaque année par l'OMS - ou des composants de ces virus. Il déclenche une réponse immunitaire précise en induisant la production d'anticorps spécifiques dirigés contre ces virus grippaux, et il apporte dès lors une protection particulière. En revanche, la préparation Oscillococcinum n'est pas en mesure de déclencher cette réponse immunitaire spécifique. L'information destinée aux patients a son sujet attire par ailleurs indirectement l'attention sur cette différence impor- tante en recommandant aux groupes à risque de consulter un médecin.

\section{Modalités de remise appropriées}

Conformément à l'article 26 de la loi sur les produits thérapeutiques (LPTh, RS 812.21), les règles reconnues des sciences pharmaceutiques et médicales doivent être respectées lors de la remise de médicaments. L'article 3 de cette loi prévoit par ailleurs que quiconque effectue une opération en rapport avec des médicaments a un devoir de diligence qui consiste à ne pas mettre en danger la santé de l'être humain et des animaux.

Les membres du corps médical et les spécialistes n'ont pas le droit de faire la promotion de certains médicaments homéopathiques ou de les vendre en tant que «vaccins homéopathiques contre la grippe» car ces allégations peuvent induire le consommateur en erreur. En effet, certaines personnes qui appartiennent à des groupes à risque et auxquelles un médecin a recommandé expressément de se faire vacciner pourraient renoncer au vaccin antigrippal actuellement recommandé par l'OFSP en entendant ce genre d'allégations, et mettraient ainsi leur santé en péril.

\section{Vous qui lisez une revue des Editions médicales suisses,}

\section{saviez-vous que ...}

- les Editions médicales suisses sont une coopération entre la Fédération des médecins suisses (FMH) et la plus ancienne maison d'édition et imprimerie au monde (les Editions Schwabe, fondées en 1488)?

- que les EMH sont les éditions de pointe en Suisse dans le domaine des journaux médicaux, avec dix revues spécialisées, des articles paraissant intégralement en ligne et un choix de livre de plus en plus large?

que toutes les revues paraissant aux EMH sont les organes officiels de publication des sociétés médicales correspondantes?

Si vous souhaitez en savoir plus sur les EMH, vous trouverez plus d'informations sous www.emh.ch.

EMH Editions médicales suisses - des publications à la pointe de la médecine 